\title{
ANALISIS KEPESERTAAN JAMINAN SOSIAL KETENAGAKERJAAN PADA PEKERJA SEKTOR INFORMAL DI KOTA PEKALONGAN
}

\author{
Arum Ardianingsih' ${ }^{1)}$, Juandy Seiver Langelo ${ }^{2)}$, Pandu Wicaksono ${ }^{3)}$ \\ ${ }^{1}$ Program Studi Akuntansi, Fakultas Ekonomi dan Bisnis, Universitas Pekalongan \\ ${ }^{2}$ BPJS Ketenagakerjaan Cabang Pekalongan \\ ${ }^{3}$ DJP Kanwil Jakarta Selatan II \\ Email: ${ }^{1}$ arumbundavina@gmail.com, ${ }^{2}$ juandyseiver@gmail.com, ${ }^{3}$ pandu.wicaksono@pajak.go.id
}

\begin{abstract}
Pekalongan is located on the nort-central coast and has a workforce of 95.581. The productive age population is generally the labor force that requires employment. Pekalongan, which is famous as a batik city, has 21.797 micro, small and medium enterprises (MSMEs). This is enough to help the population of productive age to be absorbed in the informal sector. Workers in both the formal and non-formal sectors get a salary or wages or income and social security benefits. This study aims to see the level of participation of informal workers in Pekalongan. This research is a qualitative research with triangulation analysis technique. Research data is presented descriptively. Researchers found that employment social security participation by informal sector workers in Pekalongan was still low due to the lack of socialization provided, ignorance of the procedures for registering BPJS membership and the perceived high cost of social security contributions by most informal workers.
\end{abstract}

Keywords: Employment social assurance, informal workers, Pekalongan.

\section{PENDAHULUAN}

Pekalongan adalah kota berkembang dan dikenal sebagai kota santri penghasil batik di Jawa Tengah. Letak geografis kota Pekalongan ada di jalur Pantura bagian tengah Pulau Jawa. Pekalongan adalah kota pesisir yang terkenal sebagai Kota Batik dan Kota Santri. Jumlah penduduk Kota Pekalongan sekitar 307.097 jiwa terdiri dari $50,01 \%$ berjenis kelamin lakilaki atau sebesar 153.518 dan sekitar 49,99\% berjenis kelamin perempuan atau sebesar 153.159 (BPS Kota Pekalongan, 2020). Jumlah penduduk Kota Pekalongan tersebut, tersebar pada empat kecamatan yang ada di Kota Pekalongan yaitu Kecamatan Pekalongan Barat, Pekalongan Timur, Pekalongan Utara dan Pekalongan Selatan. Jumlah angkatan kerja yang ada di Kota Pekalongan adalah sebesar 95.581 dan jumlah pengangguran adalah sebesar 9.709 (BPS Kota Pekalongan, 2020). Penduduk Kota Pekalongan biasanya bekerja pada bidang usaha batik, perdagangan, keuangan, jasa, konstruksi, perikanan dan sebagainya. Keterserapan tenaga kerja terutama di sektor informal yang merupakan Usaha
Mikro Kecil dan Menengah (UMKM) (BPS kota Pekalongan, 2020). Pekalongan sebagai Kota Santri memiliki kharakteristik sebagai berikut: pekerja informal umumnya tidak melakukan kegiatan ekonomik atau mengambil libur pada hari Jumat, pembayaran upah bagi pekerja informal dilakukan pada Kamis dengan tradisi "Pocoan", religiusitas penduduk terkadang membuat pekerja di Pekalongan memiliki pandangan berbeda terkait premi atau iuran kepesertaan jaminan sosial tenaga kerja.

Menurut Dinas Perindustrian, Koperasi dan UKM Kota Pekalongan tahun 2020, ada sekitar 21.797 UMKM yang menyebar di sentra-sentra perdagangan pada empat kecamatan yaitu Kecamatan Pekalongan Utara, Kecamatan Pekalongan Selatan, Kecamatan Pekalongan Timur, Kecamatan Pekalongan Barat. Pusat perdagangan masyarakat Pekalongan, yang juga merupakan ikon wisatawan berlokasi di beberapa titik seperti di sentra Grosir Sentono, Pasar Banjarsari dan Pasar Grogolan. Selain itu, titik produksi dan industri batik Pekalongan terletak di Kampung Batik Kauman, Kampung Batik Pesindon dan 
kawasan Buaran. Jumlah Usaha Mikro Kecil dan Menengah (UMKM) di Sentra Grosir Setono diperkirakan berjumlah 525 UMKM, Pasar Banjarsari ada sekitar 1.920 dan Pasar Grogolan sejumlah 1.329 usaha mikro kecil dan menengah (UMKM) (BPS kota Pekalongan, 2020).

Usaha Mikro Kecil dan Menengah (UMKM) banyak tumbuh dan berkembang di Pekalongan. Usaha Mikro Kecil dan Menengah (UMKM) merupakan penyumbang pertumbuhan ekonomi karena sektor industri padat karya. Para pekerja yang terserap di sektor informal selain memperoleh penghasilan, mereka juga sebenarnya membutuhkan jaminan kesejahteraan seperti tunjangan hari tua, tunjangan kecelakaan kerja dan sebagainya. Pekerja sektor informal oleh Badan Penyelenggara Jaminan Sosial Ketenagakerjaan dikategorikan sebagai peserta Bukan Penerima Upah (BPU). Mengingat begitu besarnya peran UMKM bagi perekonomian, menjadi sangat penting bagi negara hadir dalam memberikan perlindungan atas risiko yang dihadapi para pekerja informal ini (BPJS Ketenagakerjaan, 2020)

Pekerja sektor informal yaitu pekerja yang melakukan kegiatan atau usaha ekonomi secara mandiri untuk memperoleh penghasilan dari kegiatan atau usahanya tersebut. Pekerja sektor informal dapat dikelompokkan sebagai berikut: pemberi kerja, pekerja di luar hubungan kerja atau pekerja mandiri dan pekerja yang tidak termasuk pekerja di luar hubungan kerja yang bukan menerima upah, contoh; pedagang keliling atau asongan, artis, ojek dan lain-lain (BPJS Ketenagakerjaan, 2020).

Sektor informal seperti pedagang kaki lima dan ojek sebenarnya memiliki kharakteristik dan risiko pekerjaan yang cukup tinggi sehingga membutuhkan jaminan kesejahteraan bagi para pekerjanya (Pitoyo, 2007). Berdasarkan data BPS tahun 2019 jumlah penduduk Indonesia berkisar di angka 210 juta jiwa dan menyebar di 34 provinsi dari Sabang sampai Merauke. Penduduk Indonesia yang masuk angkatan kerja maka $57 \%$ tenaga kerja bekerja di sektor informal dan $43 \%$ di sektor formal. Total jumlah pekerja per Februari tahun
2021 yang sudah menjadi peserta BPJamsostek adalah 48,6 Juta dengan rincian sebagai berikut:

Tabel 1 Peserta BPJS Ketenagakerjaan

\begin{tabular}{|c|c|c|c|}
\hline Segmen & Aktif & Non Aktif & Total \\
\hline Penerima Upah & 19,26 & 20,3 & 39,56 \\
\hline $\begin{array}{l}\text { Pekerja Migran } \\
\text { Indonesia }\end{array}$ & 0,35 & 0 & 0,35 \\
\hline $\begin{array}{l}\text { Bukan Penerima } \\
\text { Upah }\end{array}$ & 2,68 & 0,55 & 3,23 \\
\hline Jasa Konstruksi & 5,46 & 0 & 5,46 \\
\hline Total & 27,75 & 20,85 & 48,60 \\
\hline
\end{tabular}

Sumber: BPJS Ketenagakerjaan, 2020

Bagaimanapun juga keberadaan pekerja sektor informal menopang kehidupan para pekerja yang belum mampu menyentuh sektor formal. Sektor pekerjaan informal memiliki ciri khas seperti upah yang lebih rendah, pekerjaan berisiko dan perlindungan atas kecelakaan kerja masih rendah. Di lain sisi, sektor informal menawarkan solusi tepat terhadap kebutuhan banyak orang untuk mendapatkan penghasilan (Taufiq, 2017).

Di Indonesia, jumlah kasus kecelakaan kerja pada tahun 2011-2014 yaitu 9.891 orang pada tahun 2011, 21.735 pada tahun 2012, 35.917 pada tahun 2013 dan 24.910 pada tahun 2014 (Kemenkes, 2015). Berdasarkan laporan tahunan BPJS Ketenagakerjaan, terdapat 123.040 kecelakaan kerja pada tahun 2017 (BPJS Ketenagakerjaan, 2017).

Data BPJS Kota Pekalongan menunjukkan sampai tahun 2020 untuk Jaminan Hari Tua sebesar Rp.158.949.168.143,03; Jaminan Kecelakaan Kerja sebesar Rp. 3.921.537.608,40; Jaminan Kematian sebesar Rp.13.111.800.000; dan Jaminan Pensiun sebesar Rp.1.964.233.873. Secara keseluruhan total kasus yang terjadi ada sekitar 23.122 yang terdiri dari 19.429 kasus klaim (JHT), 757 kasus klaim Jaminan Kecelakan Kerja (JKK), 338 kasus klaim Jaminan Kematian (JKM) dan sebesar 2.598 kasus klaim Jaminan Pensiuan (JP) (BPJS Ketenagakerjaan, 2020). Menurut ILO menyatakan separuh penduduk dunia tidak memiliki cakupan jaminan sosial dalam bentuk apapun. Di Indonesia, jumlah peserta Jaminan Kecelakaan Kerja (JKK) dan Jaminan Kematian (JKM) Bukan Penerima Upah (BPU) pada tahun 2017 yaitu sebanyak 1.714 .169 orang 
dari 63 juta orang yang bekerja di sektor informal (BPJS Ketenagakerjaan, 2017).

Undang-Undang Nomor 24 Tahun 2011 tentang Badan Penyelenggara Jaminan Sosial (BPJS), untuk mencakup kepesertaan Jaminan Sosial bagi pekerja sektor informal, maka disahkanlah Peraturan Menteri Tenaga Kerja nomor PER-24/EM/IV/2006 tentang Panduan Pelaksanaan Program Jaminan Sosial Nasional bagi tenaga kerja yang bekerja di luar hubungan kerja resmi dan selain dari pada itu ditetapkan juga Peraturan Pemerintah (PP) No.44 tahun 2015 tentang Penyelenggaraan Program Jaminan Kecelakaan Kerja dan Jaminan Kematian.

Pembangunan sektor ketenagakerjaan sebagai bagian dari upaya pembangunan sumber daya manusia merupakan satu bagian yang tidak terpisahkan dengan pembangunan nasional sebagai pengamalan Pancasila dan pelaksanaan Undang-Undang Dasar Tahun 1945. Pembanguan sektor ketenagakerjaan diarahkan pada peningkatan harkat, martabat, dan kemampuan manusia, serta kepercayaan pada diri sendiri dalam rangka mewujudkan masyarakat sejahtera, adil dan makmur baik material maupun spiritual. Konsep Negara Kesejahteraan (welfare state) berkaitan dengan kebijakan sosial yang mencakup strategi dan upaya-upaya pemerintah dalam meningkatkan kesejahteraan warganya, terutama melalui perlindungan sosial, yang mencakup jaminan sosial (berbentuk bantuan sosial dan asuransi sosial, maupun jaring pengaman sosial). Program BPJS Ketenagakerjaan atau biasa disebut dengan BPJamsostek adalah salah satu implementasi untuk mewujudkan konsep negara kesejahteraan dengan memberikan jaminan sosial kesejahteraan.

Tenaga kerja sektor informal atau tenaga kerja mandiri yaitu tenaga kerja yang melakukan pekerjaan di luar hubungan kerja dengan disertai berbagai tantangan dan risiko yang dihadapinya. Karena itu, tenaga kerja sektor informal tersebut perlu diberikan perlindungan, pemeliharaan dan peningkatan kesejahteraan sehingga pada gilirannya akan meningkatkan produktivitas nasional. Pitoyo (2007) menegaskan bahwa dalam konteks ekonomi makro, sektor informal umumnya berbentuk seperti kegiatan perdagangan, industri rumah tangga, dan penyediaan jasa-jasa kecil, telah mewarnai dan menjadi pelengkap kegiatan ekonomi nasional. Tumbuh kembang dari sektor informal ini ternyata memberikan angin segar alternatif solusi ketersediaan lapangan kerja bagi penduduk usia produktif. Kenyataannya, sektor informal telah menjadi tumpuan bagi lebih dari sepertiga pencari kerja. Angkanya dari waktu ke waktu cenderung naik, secara keseluruhan terjadi peningkatan.

Sektor informal diyakini paling tahan dengan hempasan krisis ekonomi, namun dampak pandemi Covid-19 dengan kebijakan pembatasan aktivitas di luar rumah ternyata berdampak pada sektor informal tak terkecuali di Kota Pekalongan. Pertumbuhan ekonomi Kota Pekalongan yang mengalami perlambatan sekitar satu persen dari periode sebelumnya tentu akan mengganggu sektor usaha formal dan sektor informal. Salah satu faktanya selama rentang waktu April-Agustus 2020 banyak Usaha Kecil Menengah (UKM) di sentra Grosir Setono Pekalongan banyak yang menutup usahanya dan merumahkan sementara pekerjanya. Para pekerja yang terpaksa berhenti sementara dari pekerjaan tentu tidak memiliki pemasukan apalagi untuk membayar iuran kepesertaan jaminan sosial tenaga kerja.

Program jaminan sosial tenaga kerja berusaha menanggulangi risiko-risiko sekaligus menciptakan ketenangan kerja serta memacu produktivitas kerja. Jaminan sosial tenaga kerja mendukung kemandirian dan harga diri manusia dalam menghadapi risiko sosial ekonomi. Program jaminan sosial tenaga kerja merupakan perlindungan dasar bagi tenaga kerja dan keluarganya dengan memberikan ganti rugi jika terjadi kecelakaan kerja, jaminan kematian, dan jaminan hari tua.

Berdasarkan data dari BPJS ketenagakerjaan tercatat bahwa pada tahun 2020 kepesertaan program jaminan sosial ketenagakerjaan berjumlah 48,6 juta peserta dengan rincian: peserta aktif penerima upah pada berjumlah 19,26 juta orang, pekerja penerima upah non aktif 20,3 juta orang, peserta aktif (bukan penerima upah) sebanyak 2,68 juta orang, peserta bukan penerima upah sebesar 3,23 juta orang. Di 
Kota Pekalongan sepanjang tahun 2020 tercatat jumlah tenaga kerja sektor informal yang aktif kepesertaannya adalah 9.472 tenaga kerja dan tenaga kerja sektor informal yang non aktif kepesertaannya sebesar 16.859 tenaga kerja (BPJS Ketenagakerjaan, 2020).

Fenomena di atas menarik bagi peneliti untuk kemudian merumuskan masalah penelitian yaitu mengapa kepesertaan Jamsostek untuk pekerja di sektor informal di Kota Pekalongan masih rendah? Bagaimana implementasi kepesertaan Jamsostek yang bersifat wajib bagi pekerja di sektor informal di Kota Pekalongan?

\section{METODE PENELITIAN}

Penelitian yang dilakukan adalah penelitian kualitatif. Penelitian kualitatif adalah upaya untuk menyajikan dunia sosial, dan perspektifnya pada aspek konsep, perilaku, persepsi, dan persoalan manusia yang diteliti (Moeloeng, 2018). Penelitian ini adalah penelitian kualitatif dengan pendekatan studi kasus di BPJS Ketenagakerjaan.

\subsection{Metode Pengumpulan Data}

Penelitian ini menggunakan metode pengumpulan data penelitian dengan menggunakan teknik: 1) Wawancara, dilakukan kepada partisipan atau informan. Wawancara dilakukan secara terstruktur ataupun semi terstruktur; 2) Observasi, dalam penelitian ini mengacu kepada bentuk participant obsever merupakan bentuk observasi di mana pengamat secara teratur dan berpartisipasi dalam penelitian ini. 3) Dokumentasi merupakan catatan atas peristiwa yang sudah berlaku, dokumen biasa berbentuk tulisan, gambar. Dokumentasi ini akan menjadi bukti dalam penelitian ini sehingga menjadi kredibel; 4) Internet. Search adalah telusur informasi tentang obyek penelitian tentang tambahan referensi yang bersumber dari internet yang berguna untuk melengkapi referensi penulis serta digunakan untuk menemukan fakta atau teori berkaitan tentang masalah yang diteliti.

\subsection{Instrumen Penelitian}

Instrumen penelitian ini adalah alat yang mengukur fenomena alam maupun sosial yang diamati. Adapun alat-lat yang digunakan peneliti dalam melakukan penelitian adalah perekam suara, handphone, alat tulis, daftar pertanyaan, kamera, buku dan daftar referensi lainnya.

\subsection{Teknik Analisis}

Penelitian ini menggunakan teknik analisis triangulasi yang terdiri dari: 1) Triangulasi sumber data adalah menggali kebenaran informasi tertentu melalui berbagai metode dan sumber perolehan data, misalnya, selain melalui wawancara dan observasi. Peneliti bisa menggunakan observasi terlibat (participant obervation), dokumen tertulis, arsip, dokumen sejarah, catatan resmi, catatan atau tulisan pribadi dan gambar atau foto. Tentu masingmasing cara itu akan menghasilkan bukti atau data yang berbeda, yang selanjutnya akan memberikan pandangan (insights) yang berbeda pula mengenai fenomena yang diteliti. Berbagai pandangan itu akan melahirkan keluasan pengetahuan untuk memperoleh kebenaran handal; dan 2) Triangulasi teori. Hasil akhir penelitian kualitatif berupa sebuah rumusan informasi atau thesis statement. Informasi tersebut selanjutnya dibandingkan dengan perspektif teori yang relevan untuk menghindari bias individual peneliti atas temuan atau kesimpulan yang dihasilkan. Selain itu, triangulasi teori dapat meningkatkan kedalaman pemahaman asalkan peneliti mampu menggali pengetahuan teoretik secara mendalam atas hasil analisis data yang telah diperoleh. Analisis data penelitian disajikan dalam bentuk Deskriptif.

\section{HASIL DAN PEMBAHASAN \\ 3.1. Angkatan Kerja, Pekerja Formal dan Pekerja informal \\ Survey yang dilakukan oleh Badan Pusat} Statistik (BPS) tahun 2020 menunjukkan jika penduduk Indonesia bertambah 32,05 juta dalam kurun 2010-2020. Indonesia memiliki populasi penduduk mencapai 270,02 juta jiwa per September 2020. Laju pertumbuhan penduduk rata-rata ialah 1,25 persen per tahun. Sebaran penduduk Indonesia, masih terkonsentrasi di Pulau Jawa, yaitu 151,59 juta jiwa atau 56,10 persen dari seluruh penduduk. Sebaran terbesar kedua adalah di Pulau Sumatra, dengan jumlah 58,56 juta orang atau 21,68 persen. Pulau Sulawesi memberi 
kontribusi sebaran sebesar 7,36 persen. Posisi berikutnya adalah ada di Pulau Kalimantan 6,15 persen dan terakhir sebaran penduduk ada di Indonesia bagian timur yaitu wilayah Bali-Nusa Tenggara dan Maluku-Papua masing-masing sebesar 5,54 dan 3,17 persen. Hasil Sensus Penduduk BPS tahun 2020, mencatat mayoritas penduduk Indonesia didominasi oleh generasi Z (lahir kurun 1997-2012) dan generasi milenial (lahir pada kurun 1981-1996).

Indonesia diberkahi dengan bonus demograsi penduduk karena struktur kependudukan didominasi oleh generasi $\mathrm{Z}$ sebanyak 27,94 persen dari total populasi dan generasi milenial sebanyak 25,87 persen. Persentase penduduk usia produktif (15-64 tahun) terhadap total populasi pada 2020 sebesar 70,72 persen. Sedangkan persentase penduduk usia non produktif (0-14 tahun dan 65 tahun ke atas) tercatat sebesar29,28\% pada 2020 (BPS, 2020). Sehingga tampak sekali persentase penduduk usia produktif tampak sedemikian besar.

Angkatan kerja didefinisikan sebagai penduduk yang berada pada usia produktif. Pekerja adalah setiap orang yang bekerja dengan menerima gaji, upah, atau imbalan dalam bentuk lain. Angkatan kerja di tahun 2020 mencapai sekitar 70,79 persen dari keseluruhan total penduduk Indonesia (BPS, 2020). Sedangkan persentase penduduk usia non produktif (0-14 tahun dan 65 tahun ke atas) tercatat sebesar 29,28\% pada 2020. Berdasarkan data BPS Kota Pekalongan tahun 2020, dari jumlah penduduk Kota Pekalongan yang sebesar 307.097 jiwa, yang masuk pada angkatan kerja sejumlah 95.281 jiwa dengan total tingkat partisipasi angkatan kerja sebesar 72,32 persen. Penduduk yang masuk pada angkatan kerja di Kota Pekalongan ini terserap di lapangan pekerjaan terutama bidang perdagangan besar, eceran, rumah makan, hotel terutama perdagangan batik, tenun dan berbagai produk craft serta bidang kontruksi atau bangunan.

Pekerja penerima upah (pekerja formal) dan anggota keluarganya terdiri dari PNS, anggota TNI, anggota POLRI, pejabat negara, pegawai pemerintah non pegawai negeri dan Pegawai swasta. Pekerja bukan penerima upah (pekerja informal) dan anggota keluarganya adalah pedagang, pengamen, sopir angkot, tukang becak, tukang cukur, tukang pijat, dan lain-lain. Penduduk yang bekerja baik di sektor formal maupun sektor informal tentu akan memperoleh gaji dan/atau penghasilan dari kegiatan ekonominya. Selain itu, para pekerja tersebut pasti memerlukan sebuah jaminan sosial kesejahteraan. Penyelenggaraan jaminan sosial kejahteraan di Indonesia diselenggarakan oleh BPJS Ketenagakerjaan.

\subsection{Jaminan sosial ketenagakerjaan}

Undang-Undang Nomor 40 Tahun 2004 tentang Sistem Jaminan Sosial Nasional adalah salah satu bentuk perlindungan sosial untuk menjamin seluruh rakyat agar dapat memenuhi kebutuhan dasar hidupnya dengan layak. Jaminan sosial menurut Undang-Undang Nomor 13 Tahun 2003 dijelaskan secara tersirat di dalam Pasal 99, Pasal 100, dan Pasal 101 isinya adalah setiap pekerja atau buruh dan keluarga berhak kerja. Tujuan program ini untuk meningkatkan kesejahteraan bagi buruh dan keluarganya. Di dalam Pasal 100 Ayat (2) Undang-Undang Nomor 13 Tahun 2003 tentang Ketenagakerjaan ditegaskan dalam hal fasilitas dan penyediaan jaminan sosial dengan memperhatikan kondisi dari pekerja/buruh itu sendiri, serta ukuran kemampuan dari perusahaan.

Penelitian ini dilakukan di Kota Pekalongan terkait kepesertaan pekerja informal belum terlaksana secara optimal atas program jaminan sosial dalam rangka meningkatkan kesejahteraan bagi pekerja informal. Peraturan perundang-undangan hanya memberikan jaminan sosial tenaga kerja bagi pekerja formal. Serta dalam Pasal 103 Ayat (3) Undang-Undang Nomor 13 Tahun 2003 tentang Ketenagakerjaan, dijelaskan bahwa pemerintah, perusahaan, pekerja atau buruh dan serikat pekerja mengembangkan usaha koperasi serta usaha produktif.

Ada tiga jenis perlindungan sosial yang diberikan untuk tenaga kerja yaitu perlindungan sosial, perlindungan teknis dan perlindungan ekonomis. Perlindungan sosial yaitu suatu perlindungan dengan tujuan agar pekerja atau buruh mengenyam dan mengembangkan kehidupannya agar menjadi manusia seutuhnya. 
Perlindungan sosial disebut dengan kesehatan kerja. Perlindungan teknis yaitu jenis perlindungan berkaitan dengan usaha-usaha untuk menjaga agar pekerja atau buruh terhindar dari bahaya kecelakaan akibat alatalat kerja atau bahan yang dikerjakan, perlindungan ini lebih sering disebut sebagai keselamatan kerja. Perlindungan ekonomis yaitu suatu jenis perlindungan yang berkaitan dengan usaha-usaha untuk memberikan kepada pekerja atau buruh suatu penghasilan yang cukup guna memenuhi keperluan sehari-hari bagi dirinya dan keluarganya. Termasuk dalam hal pekerja atau buruh tidak mampu bekerja karena sesuatu di luar kehendaknya. Perlindungan jenis ini biasanya disebut dengan jaminan sosial.

\subsection{Pelaksanaan Badan Penyelenggara Jaminan Sosial terhadap Pekerja Formal dan Pekerja Informal.}

Program pelaksanaan penyelenggara jaminan sosial tenaga kerja bagi pekerja informal merujuk pada Undang-Undang Nomor 13 Tahun 2003 tentang Ketenagakerjaan, meliputi: 1) Jaminan Kecelakaan Kerja (JKK); 2) Jaminan Kematian (JKM); dan 3) Jaminan Hari Tua (JHT). Iuran ditetapkan oleh BPJS Ketenagakerjaan adalah nilai nominal tertentu berdasarkan upah sekurang-kurangnya setara dengan Upah Minimum Provinsi atau Kabupaten/Kota. Besaran iuran yang harus dibayarkan menurut BPJS Ketenagakerjaan yaitu: 1) Jaminan Kecelakaan Kerja sebesar 1\% (satu persen); 2) Jaminan Hari Tua sebesar 2\% (dua persen); dan 3) Jaminan Kematian. dengan iuran terendah sebesar $\mathrm{Rp} 6.800,-$, peserta informal sudah dapat memiliki perlindungan JKK dan JKM. Jumlah premi tersebut tergolong murah dibandingkan asuransi swasta, bahkan premi tersebut dapat memberikan manfaat yang besar oleh peserta jika terjadi risiko seperti kecelakaan kerja.

Banyaknya pekerja informal di Kota Pekalongan yang belum ikut kepesertaan jaminan sosial ketenagakerjaan karena kurangnya sosialiasi akan program ini. Kota Pekalongan sebagai Kota Santri memiliki kekuatan dalam penokohan alim ulama. BPJS Ketenagakerjaan perlu juga melakukan sosialisasi program jaminan sosial ini dengan melibatkan tokoh ulama di Kota Pekalongan. Sosialisasi program juga harus menyeluruh pada dimensi pekerja sektor informal dan dilakukan secara kontinyu dan berkelanjutan.

Pada dasarnya pemberdayaan harus dilakukan kepada pekerja baik di sektor formal dan informal. Pemberdayaan tenaga kerja merupakan suatu kegiatan yang terpadu dengan melibatkan antar departemen untuk memberikan kesempakatan kerja yang seluasnya-luasnya bagi tenaga kerja. Memperbaiki dan meningkatkan jaminan sosial merupakan bagian terpenting dari usaha pemerintah dan masyarakat di samping upah yang cukup serta syarat kerja yang manusiawi. Jaminan sosial adalah usaha untuk memperoleh perbaikan upah dengan memperoleh manfaat ekonomis dengan bentuk lainnya. Dengan kata lain, kesejahteraan tenaga kerja memiliki indikator perolehan gaji, upah, penghasilan dan keikutsertaan dalam program jaminan sosial BPJS Ketenagakerjaan.

Dalam tahapan kesejahteraan pekerja informal, maka pemberian fasilitas kesejahteraan bagi pekerja informal melalui sosialisasi program perlu dilakukan. Bentuk tanggung jawab sosial negara sebagai implementasi konsep kesejahteraan adalah memberikan kesempatan bagi pekerja informal atas hak-haknya melalui suatu badan penyelenggara jaminan sosial yaitu BPJS Ketenagakerjaan. Hal lain yang menjadi catatan adalah pekerja di sektor informal biasanya adalah tenaga kerja yang umumnya tidak terserap di sektor formal. Pekerja-pekerja ini memiliki rentang usia di atas 35 tahun sehingga sangat susah untuk bergabung di program jaminan sosial ketenagakerjaan.

Data BPJS Ketenagakerjaan terkait dengan rasio kasus klaim kepesertaan jaminan sosial dijelaskan sebagai berikut: jumlah klaim sepanjang tahun 2020 adalah sebesar 23.122 kasus dan memiliki jumlah kasus tertinggi pada bulan Februari untuk klaim Jaminan Hari Tua (JHT) sebesar 2.140 kasus, Jaminan Kecelakaan Kerja (JKK) sebesar 69 kasus dan Jaminan Kematian (JKM) sebesar 24 kasus atau secara keseluruhan yaitu sebesar 2.233 kasus, kemudian jumlah klaim kasus urutan kedua ada di bulan Juni secara keseluruhan ada 2.148 
kasus terdiri dari klaim Jaminan Hari Tua (JHT) sebesar 2.011 kasus, Jaminan Kecelakaan Kerja (JKK) sebesar 100 kasus dan Jaminan Kematian (JKM) sebesar 37 kasus. Bulan Februari dan Juni adalah bulan dengan klaim kasus cukup anomali dibandingkan bulan Januari, Maret, April, Mei, Juli, Agustus, September, Oktober, November dan Desember tahun 2020. Jumlah klaim kasus tertinggi atas Jaminan Kecelakaan Kerja (JKK) ada di bulan Juli yaitu dengan jumlah 107 klaim kasus, melampaui klaim kasus bulan Juni. Sementara jumlah klaim Jaminan Kematian (JKM) ada di bulan November sebanyak 39 klaim kasus dan diikuti di bulan Juni sebanyak 37 klaim kasus JKM.

Apabila dilihat dari jumlah klaim kasus di atas seperti mengikuti fluktuasi dari dampak pandemi Covid-19 yang melanda Indonesia khususnya Kota Pekalongan sejak bulan Februari 2020 sampai saat ini. BPJS Ketenagakerjaan di tahun 2021 menargetkan sekitar 17.776 kepesertaan pekerja sektor informal yang aktif dengan tingkat realisasi target sebesar 10.217 atau sebesar $57,48 \%$. Artinya baru separuh target kepesertaan bagi pekerja informal yang terlampaui. Padahal jika dilihat manfaat ekonomi dari keikutsertaan pekerja informal dalam program jaminan sosial kesejahteraan ini adalah membantu diri dan anggota keluarganya tetap sejahtera di tengah badai pandemi Covid-19. Dalam konteks ini pekerja informal belum memahami manfaat yang akan diperoleh dengan mengikuti program jaminan sosial ketenagakerjaan yang diwajibkan oleh pemerintah. Alasannya, sebagian masyarakat Kota Pekalongan sangat religius sehingga ada anggapan keikutsertaan program ini bisa menimbulkan riba.

\section{KESIMPULAN}

BPJS Ketenagakerjaan atau biasa dipanggil BPJamsostek hadir sebagai Badan Hukum Publik dan langsung bertanggungjawab kepada Presiden Republik Indonesia, tugas pokok BPJamsostek yaitu memberikan perlindungan bagi tenaga kerja untuk mengatasi risiko sosial ekonomi tertentu akibat hubungan kerja. Jaminan sosial ketenagakerjaan ini diberikan kepada pekerja sektor formal dan pekerja sektor informal.

Bentuk jaminan sosial ketenagakerjaan bagi pekerja sektor informal adalah Jaminan Hari Tua (JHT), Jaminan Kecelakaan Kerja (JKK) dan Jaminan Kematian (JKM). Kota Pekalongan sebagai kota berkembang dengan banyaknya industri batik, perdagangan besar, kuliner, usaha kelontong merupakan beberapa bentuk dari Usaha Mikro Kecil dan Menengah (UMKM) yang ada. Di Kota Pekalongan menurut data Dinas Perdagangan, Koperasi dan UMKM Kota Pekalongan tahun 2020 mencatat ada sekitar 21.797 UMKM yang memiliki ciri khas yaitu usaha padat karya dan mampu menyerap tenaga kerja. Usaha Mikro Kecil dan Menengah (UMKM) ini merupakan sektor informal. Kepesertaan pekerja sektor informal di Kota Pekalongan diawal tahun 2021 adalah sekitar 10.217 atau sebesar $57,48 \%$ dari total target kepesertaan yang sebesar 17.776 kepesertaan pekerja sektor informal.

Beberapa alasan rendahnya kepesertaan pekerja di sektor informal karena pertama, kurangnya sosialisasi manfaat yang diberikan para regulator terkait jaminan sosial ketenagakerjaan sehingga para pekerja sektor informal tidak mengetahui. BPJamsostek perlu berkolaborasi dengan tokoh masyarakat untuk bergerak bersama memberikan perlindungan kepada masyarakat yang bekerja sebagai pekerja informal. Kedua, pekerja sektor informal tidak mengetahui bagaimana cara untuk melakukan pendaftaran keikutsertaan program ini. Ketiga, kearifan lokal dari masyarakat Pekalongan dengan tingkat kepercayaan keagamaan tinggi dan menilai premi keikutsertaan jaminan sosial ketenagakerjaan sebagai sesuatu yang bernilai riba.

\section{REFERENSI}

Badan Pusat Statistik, 2020. "Sensus Kependudukan". www.bps,go.id.

BPS Kota Pekalongan. 2020. “Pekalongan dalam angka tahun 2020". BPS kota pekalongan.go.id.

ILO, "Jaminan Sosial bagi Tenaga Kerja di Sektor Informal di Indonesia Mencari 
Program Fleksibel yang Ditargetkan," ILO dan Jamsostek. 2010. www.ilo.org.

Lexy J. Moleong, M.A.2018. Metodelogi Penelitian Kualitatif. PT.Remaja

Rosdakarya. Bandung.

Permennaker Nomor 24 Tahun 2006 tentang Pedoman Penyelengaraan Program Jaminan Sosial Tenaga Kerja bagi Tenaga Kerja yang Melakukan Pekerjaan di Luar Hubungan Kerja.

Peraturan Pemerintah(PP)No.44 tahun 2015 tentang Penyelenggaraan Program Jaminan Kecelakaan Kerja dan Jaminan Kematian.

Peraturan Pemerintah(PP) Nomor 44 Tahun 2015 tentang Penyelenggaraan Program Jaminan Kecelakaan Kerja dan Jaminan Kematian.

Peraturan Menteri Tenaga Kerja nomor PER24/EM/IV/2006 tentang Panduan Pelaksanaan Program Jaminan Sosial Nasional bagi tenaga kerja yang bekerja di luar hubungan kerja resmi.

Pitoyo, Agus Joko. 2007. Dinamika Sektor Informal di Indonesia: Prospek Perkembangan, dan Kedudukannya dalam Sistem Ekonomi Makro. Populasi Vol. 18 No. 2 Tahun 2007

Republik Indonesia. 2004. Undang-undang sistem jaminan sosial nasional no. 40 Tahun 2004.

Taufiq, N, 2017. Pengaruh dinamika sektor pekerjaaan terhadap dinamika kemiskinan di Indonesia: The effect of employment dinamics in Indonesia. November 2018 <website e-journal kemsos.go.id, 2017>.

Undang-Undang Dasar 1945 .

Undang-undang Nomor 24 Tahun 2011 tentang Badan Penyelenggara Jaminan Sosial

Undang-undang Nomor 40 Tahun 2004 tentang Sistem Jaminan Sosial Nasional www.bpjsketenagakerjaan.go.id

Undang-Undang Nomor 13 Tahun 2003 tentang Ketenagakerjaan 